\title{
A CHRONOLOGICAL CATALOGUE OF SINKHOLES IN ITALY: THE FIRST STEP TOWARD A REAL EVALUATION OF THE SINKHOLE HAZARD
}

\author{
Mario Parise, Carmela Vennari
}

CNR-IRPI, Via Amendola 122-I, 70126,Bari,Italy, m.parise@ba.irpi.cnr.it

\begin{abstract}
Among the many different types of geological hazards affecting the Italian territory, sinkholes have often been underestimated (if not neglected entirely), and only in some sectors of the country have they been effectively considered in hazard and risk analysis. Nevertheless, sinkholes affect large parts of Italy, covering the whole territory with a variety of typologies, and exhibit both natural and anthropogenic origin. The latter clearly originate from the long history of Italy, with the complex historical vicissitudes that have characterized this territory, during which different types of artificial cavities have been realized underground for different purposes in different epochs. Over time, many of these cavities have been abandoned, and the consequent loss of memory resulted in their inclusion in newly developed parts of towns, thus creating a serious risk to the built-up environment above.
\end{abstract}

Starting from these considerations, an archival research was started to collect information about the occurrence of sinkholes in Italy, with particular attention to their precise site and date of occurrence, in order to make an effort in assessing, respectively, the susceptibility and the hazard related to the particular phenomenon under study. As concerns date of occurrence, the accuracy of the information is provided (depending upon the amount of available data), with the highest quality when hour, day, month and year of occurrence are indicated, and a decrease in quality when one or more of these data are lacking. In order to be included in the database, at least some kind of temporal reference (even if general) of the sinkhole has to be known.

The present article illustrates the first results of this study, describing the catalogue obtained so far which consists of more than 650 sinkhole events for which at least some information about temporal occurrence of the event have been found. The data, even though not definitive, represent a good starting point for analysis of the sinkhole hazard at a national scale, aimed at increasing the level of attention by scientists, practitioners and authorities on this subtle hazard.

\section{Introduction}

Italy is affected by a high number of geological hazards that cause severe losses every year and are at the origin of many casualties, thus producing a very high toll to the society. Earthquakes, volcanic eruptions, slope movements, and floods are probably the most wellknown and studied hazards in the country (Guzzetti et al., 1994; Boschi et al., 2000; Gasperini \& Valensise, 2000). To these, further phenomena, at least in part caused by man, have to be added: for instance, wildfires, with the consequent effects on loss of vegetational cover and soil erosion.

Within such a framework, sinkholes have often been under estimated if not entirely neglected, and only in some sectors of Italy have they been effectively considered in hazard and risk analysis. Nevertheless, sinkholes affect large parts of the country, covering the whole territory with a variety of typologies, and showing both natural and anthropogenic origin. The latter clearly derives from the long history of Italy, with the complex historical vicissitudes that have characterized this territory, during which different types of artificial cavities have been realized underground for different purposes in different epochs (Parise, 2012). Over time, many of these cavities have been abandoned, and the loss of memory about such features resulted in their inclusion in newly developed parts of towns, thus creating a serious risk to the built-up environment above (Pepe et al., this volume).

When unstable underground caves are located below buildings or infrastructures, their collapse may result in significant economic losses. Further, the rapid evolution of the failure processes (in particular during the catastrophic phase of rupture, and the resulting sudden collapse) can also represent in some cases a risk to human life. In this regard, the high rate of evolution is related to either the propagation of fractures through 
the intact rock surrounding the caves (Kowalski, 1991; Liu et al., 2000) or the slip movement of rock portions along pre-existing discontinuities, both of these being generally controlled by progressive failure conditions, that sometimes induce catastrophic collapse (Diederichs and Kaiser, 1999a, b; Lanaro, 2000; Starzec and Tsang, 2002; Pine et al., 2006; Parise, 2008; Parise and Lollino, 2011).

Several aspects make sinkholes differ from other types of hazards, such as landslides and flooding: first, a sinkhole is a phenomenon which at the surface appears as punctual (site-located), and that is found at a very specific site, generally of limited dimensions. This, however, does not mean that the affected area is limited to that point, since underground the caves responsible for the event may also show a wide extension. Consequently, sinkholes are rarely taken into account in the analysis of hazard and risk assessment, even though they may represent the main geological hazard in specific settings.

With respect to natural sinkholes, these typically are found in areas with soluble rocks affected by karst processes, or alluvial sediments in peculiar geological situations. Thus, the zonation of the sinkhole-prone areas may be done for natural sinkholes based solely upon geology as a first approximation.

The situation is quite different for anthropogenic sinkholes, because the distribution of artificial cavities depends upon many other factors, such as historical, cultural, and social issues. In this regard, it is important to highlight that we excluded from the catalogue all those events of anthropogenic origin which were reported as due to water leakage from pipelines, with the consequent erosion in the subsoil, without any evidence of an underground man-made cave. Thus, in our catalogue anthropogenic sinkhole means a sinkhole caused by the presence of a cavity created by man underground, regardless of the cavity typology.

In general, there is more detailed information about anthropogenic sinkholes than for those of natural origin. This because the first category generally affects built-up areas, and causes direct damage and negative effects to society (blockage of roads and communication routes, disrupting lifelines, etc.). At least some of these effects are generally reported, which helps in defining the time and site of occurrence of the phenomenon.
In the case of natural sinkholes, the related surface effects may go unnoticed, especially when they occur in rural areas; further, land owners often prefer not to spread the news, in order to avoid loss of value of the land.

In Italy, some databases about sinkholes are already available. The most significant are managed by ISPRA and by University of Rome Tre. These databases, however, do not focus in particular neither on time of occurrence of the sinkholes, nor in the distinction between the natural or anthropogenic origin. They are not specifically addressed to assessment of the sinkhole hazard, but rather to indicate the areas of the territory where sinkholes do occur (at the national or regional scale). In several cases they also include unverified information, or a number of cases related to leakage from water pipelines, which may bring to wrong or incorrect conclusions.

To fully evaluate the hazard related to natural danger, the return time of the phenomena needs to be estimated. Lacking such information, there is no possibility to effectively determine the hazard, and the research has generally to stop at the stage of susceptibility assessment (Varnes, 1984). Thus, availability of documentation about past events is crucial.

Unfortunately, very often the record of what occurred even in the recent past is difficult to be found. Further, when some documentation is available, most of the information show low reliability, and are based on memories, or are not supported by real documents. This represents a very important drawback that often has to be faced in the search for historical information on different types of hazards (see, for instance, Calcaterra \& Parise, 2001; Glade et al., 2001; Calcaterra et al., 2003).

Actually, it would be useful to better understand the conditions that are likely to cause sinkhole formation (Benson at el., 2003). One of the purposes of this research is to evaluate the timing of sinkholes in Italy, also to provide clues for assessing the specific settings (climatologic, meteorologic, seismic, etc.) under which they formed.

There is a great variety of sinkhole types in Italy (Buchignani et al., 2008; Nisio, 2008; Del Prete et al., 2010; Margiotta et al., 2012), with events triggered by very different factors, including rainfall, seismic shocks 
and human actions. In fact, even though most of the cases seem to occur in response to meteoric events, and the deriving runoff and groundwater circulation, reactivation of sinkholes may be a consequence of earthquakes too, as recently experienced at the Sinizzo Lake after the Abruzzo earthquake in 2009 (Figure 1; Parise et al., 2010); or be originated by construction of buildings, vibrations due to traffic, or excavations from putting in operation or maintaining the network of pipelines. Further, the interest on sinkholes is increasing in the last years, which has allowed identification of sinkhole features also in geological settings never before considered, such as offshore (see at this regard the work by Taviani et al., 2012).

In the following sections, we will describe the structure of the catalogue, and illustrate the first outcomes, before presenting the future perspectives of this research activity on sinkholes.

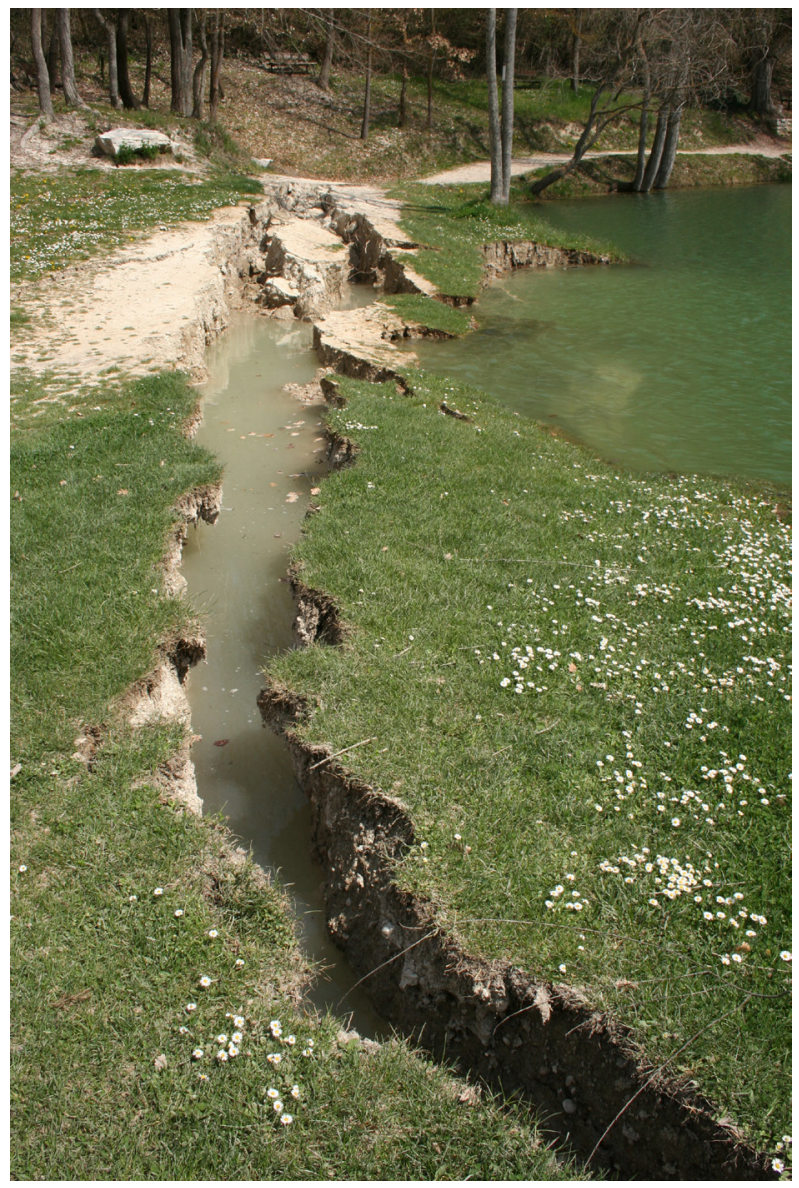

Figure 1. Development of cracks along the shores of Sinizzo Lake (Abruzzo), in the aftermath of the Mw 6.3 L'Aquila earthquake, on April, 6, 2009.

\section{The catalogue structure}

Based upon the considerations presented in the previous section, the catalogue on Italian sinkholes (Figure 2) has been structured giving a crucial role to the information on time of occurrence of the sinkhole, and, in addition, clearly expressing a level of accuracy about this specific data. Date of the event is subdivided into four different fields, covering hour, day, month and year. Ideally, availability of all data represents the best condition (high category class). Being aware of the difficulties in finding such a detail, we also considered the possibility to have available only a part of the timing information, which in many cases is likely limited to month and year (medium category class). This in particular occurs for sinkholes located in rural areas, where generally no record or observation is recorded soon after the occurrence of the event.

Lacking a temporal reference of the sinkhole, it is possible to use multi-temporal analysis of available aerial photographs and maps to preliminary define a time range (low category class) for occurrence of the event, as shown in the study by Festa and co-workers (2012). In

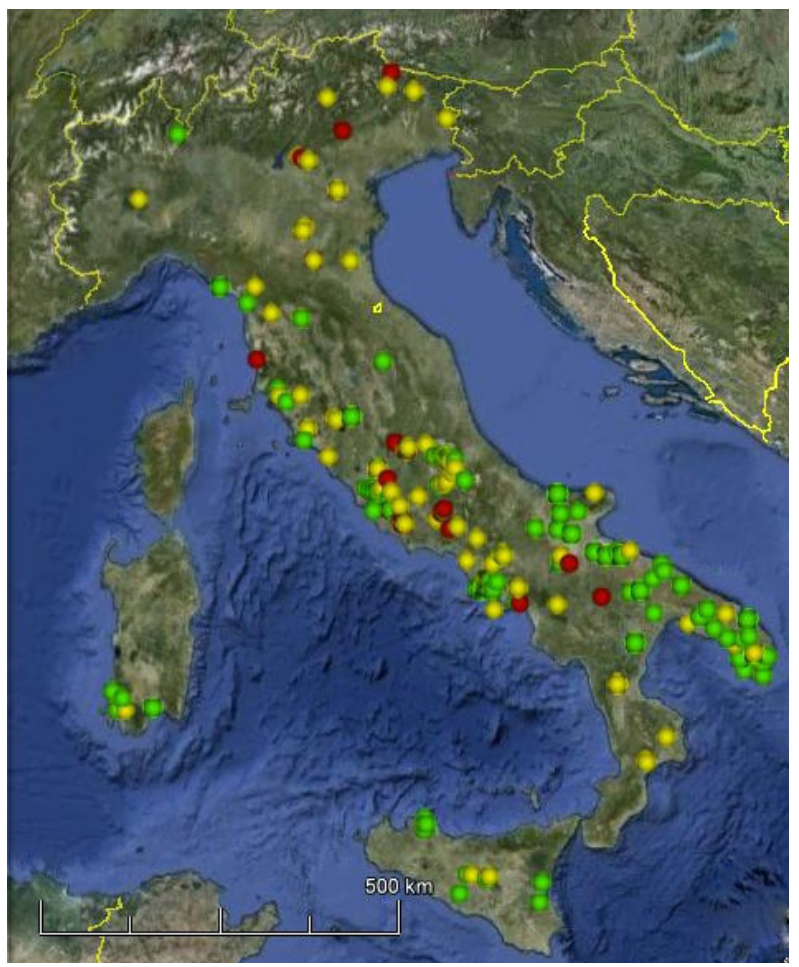

Figure 2. Distribution of the sinkholes listed in the catalogue over the Italian territory $(n=652)$. The different colors indicate the degree of certainty in the location: green means certain location, yellow uncertain location, and red very generic indication about the site of occurrence. 
first approximation, such an approach allows to get an idea of the time evolution at a particular site. Availability of at least one field among the four dealing with timing is mandatory to include an event in the database. When the event is included, a degree of accuracy is also attributed, with the highest degree corresponding to all the fields being filled, whilst progressively lower information move the degree of reliability toward the lowest values.

This is a very important aspect that strongly makes our catalogue differ from other sinkhole databases in Italy. As aforementioned, we consider of crucial importance the knowledge of the time of occurrence, as a fundamental element to allow an estimate of the likely return time of the events, and therefore to assess the sinkhole hazard.

The sources of historical information include newspaper clips, scientific literature, and critical analysis of the available database on sinkholes. Furthermore, regional and local history books, and transcriptions or translations of old chronicles have also been considered. Some additional information derived from reports prepared by regional and local technical offices to describe the effects of single events and their consequences, and from unpublished technical reports of practitioners. Eventually, our original field data and surveys during the last 15 years provided additional information for some regions of southern Italy (namely, Apulia, Campania, and Calabria). A few bachelor degree theses also dealt with the topic, and were particularly useful for specific areas (for instance, the town of Palermo, with the work by Sottile, 2010). For some recent events, new or updated information was obtained through the Internet, in particular by searching for local daily reports and online newspaper. This is certainly one of the most useful sources nowadays, and has become increasingly used to collect data on a variety of natural hazards.

Regarding sinkholes, one of the few published examples of the use of internet information was recently presented by Brinkmann and Parise (2010). They used two sources of data for recently formed sinkholes in Florida, in the attempt to determine the timing history of sinkholes at Tampa and Orlando: the Florida Geological Society database and the LexisNexis database of newspaper articles. From such sources, a good number of information was extracted on several tens of sinkholes, which allowed the authors to define a model for the timing of sinkholes associated with seasonality, at the same time highlighting the growing public interest in sinkhole formation in the region (Brinkmann and Parise, 2010).

The other fields taken into account in the catalogue refer to origin of the sinkhole (divided into natural, anthropogenic, and of unknown origin), information on the triggering factor, the main morphometric parameters of the sinkhole (diameter, depth), and an indication of the occurrence as first-time event, or re-activation of an already known phenomenon. Regarding origin, sinkholes were included in the "unknown" category when no clear information about the nature of the underground cavities (natural or man-made) responsible for the phenomenon was available.

Damage recorded as a consequence of the occurrence of sinkholes provides very important information. Evaluating damage allows, as a matter of fact, assessment of the effects on anthropogenic structures of a specific hazard, in this case represented by a sinkhole. It is not easy to have a complete figure of the damage resulting from natural and/or anthropogenic hazards: in most cases the information are qualitative, especially for the oldest events. In any case, having the possibility to make a general framework of the damage occurred is a good starting point in the effort to assess the vulnerability linked to sinkholes.

With respect to location, the sites affected by sinkholes were positioned using Google Earth as a base. They were also mapped at 1:25,000 scale, using the topographic base maps by the Italian National Geographical Institute.

The sinkholes are represented (Figure 2) with different colors which indicate the level of uncertainty in location of the event: green is for certainty in the location, yellow for uncertainty, red for very generic indication of the site affected by the sinkhole.

\section{Preliminary evaluation of the catalogue outcomes}

In total, 652 sinkholes, for which availability of temporal references has been found, are included so far in the catalogue. Of these, about 100 are anthropogenic sinkholes in the town of Palermo, Sicily, and have been extracted from the work by Sottile (2010), whilst about 150 entries are from the work by Guarino \& Nisio (2012) dealing with anthropogenic sinkholes in the town of Naples, Campania, one of the most well known sites in 
Italy for sinkhole problems. Overall, more than half of the sinkholes in the catalogue (precisely, 54\%) have an anthropogenic origin, whilst a quarter of the entries are due to natural caves, and for the remaining cases no clear origin of their formation has been found so far (Figure 3).

In the catalogue, information on the timing and location of events is generally accurate. Geographical accuracy decreases going back in the past. Historical documents and chronicles are typically more accurate in providing figures for casualties and damage of natural hazards, rather than on their precise location and date (Salvati et al., 2010).

As previously stated, timing of occurrence represents the main information needed for inclusion of a sinkhole in the catalogue. The best situation, represented by availability of all the data concerning time of occurrence (high category class) is satisfied in very few cases (precisely, 22 events, corresponding to $3 \%$ of the database; Figure 4 ). However, if we consider the information where at least the day, month, and year is known, an overall percentage of $68 \%$ is reached (high + medium-high categories in the chart in Figure 4). Lower percentages characterize the other categories, where the availability of information about time of occurrence of the sinkhole progressively reduces (medium, medium-low, and low categories).

With respect to the chronological distribution of the sinkholes, the oldest information goes back to historical times for a few cases; some sinkhole events are documented since the $13^{\text {th }}$ century, even though most of the information concentrates starting from the $19^{\text {th }}$ century. For anthropogenic sinkholes, the oldest documented event goes back to the end of the $19^{\text {th }}$ century in Calabria.

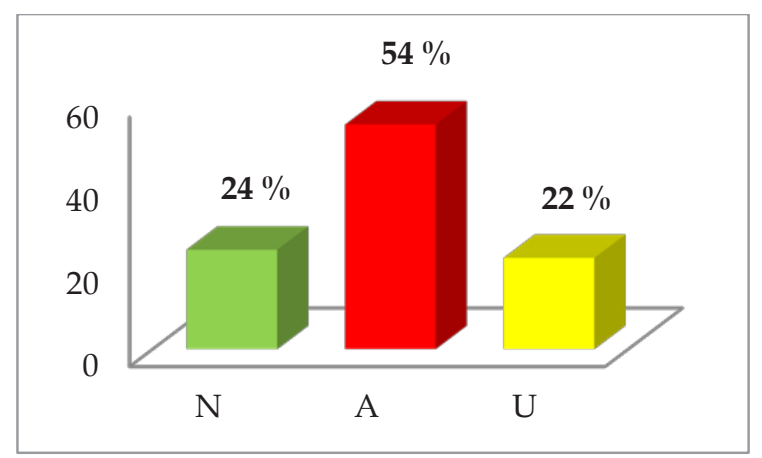

Figure 3. Histogram showing the origin of sinkholes in the catalogue: $N=$ natural sinkholes; $A=$ anthropogenic sinkholes; $U=$ sinkholes of unknown origin.

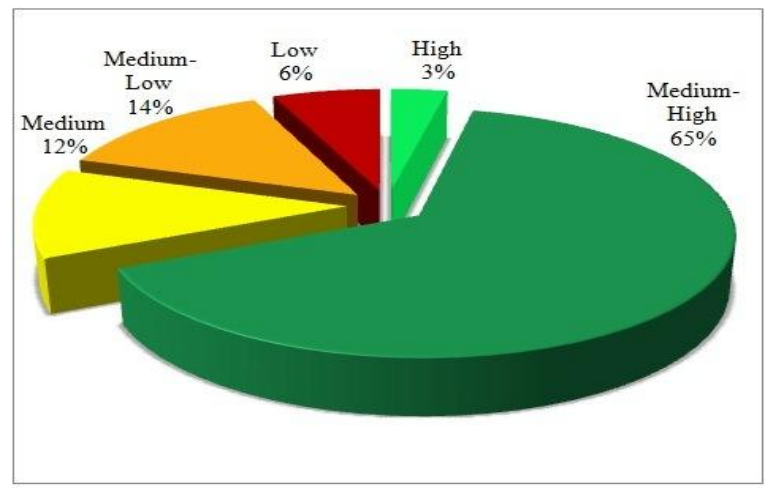

Figure 4. Pie chart showing the percentage of accuracy of date of occurrence of sinkholes.

The events are not equally distributed over time. There is an overall increase in the last decades, which, on the other hand, is not always accompanied by adequate completeness in the temporal information. In other words, it was expected that, moving toward recent times, a higher degree of precision in the temporal information could be reached. Nevertheless, it is very common that, even for recent occurrence of sinkholes, the accuracy in the timing of occurrence may be low. In practice, if the sinkhole is recorded or witnessed soon after its occurrence, and made the object of a description in reports or chronicles, timing is typically accurate; when, on the other hand, the news is obtained later on, only generic information, generally limited to month and year, have to be registered.

As noted by previous scholars dealing with natural hazard catalogues (Guzzetti, 2000; Guzzetti et al., 2005; Salvati et al., 2010), it is very difficult to quantify the incompleteness of non-instrumental records of natural events. Lack of occurrence of events in a given period may in fact either due to catalogue's incompleteness or to changes in the conditions that led to trigger the event (i.e. climate, land-use changes, human actions, and so on).

Information on the location (either precise or approximate) of the sinkhole is available for most of the events in the catalogue. Namely, location of $72 \%$ is certain, whilst $21 \%$ of the events has some degree of uncertainty, and only the remaining 7\% (47 sinkholes) presents a very generic indication about the site of occurrence of the sinkhole.

Sites affected by sinkholes with a chronological reference are not distributed equally in Italy. Their distribution is 
essentially dependent upon the presence of soluble rocks or alluvial deposits as regards the natural sinkholes, whilst the location of the anthropogenic sinkholes is essentially a function of the presence of artificial cavities. Thus, some towns presents a very high number of phenomena, which is also dependent on a better record of the sinkhole events (this is the case, for instance, of towns as Naples, Campania, and Palermo, Sicily; see Sottile, 2010; Guarino and Nisio, 2012).

Concerning the spatial distribution of sinkholes (Figure 2 and Table 1), some regions show very high numbers, whilst others are much less represented. Two regions (Molise and Valle d'Aosta) out of the 21 in which Italy is subdivided so far do not have any event in the catalogue. This inhomogeneity derives from greater availability of specific works on the topic in particular regions, and/or from direct experience in some others.

Nevertheless, we expect that the future data entry of other sinkholes will in some ways reduce this gap. In any case, it is well known that regions such as Campania,

Table 1. Regional distribution of the sinkholes in the catalogue. The origin of sinkholes is also shown ( $N=$ natural; $A=$ anthropogenic; $U=$ unknown).

\begin{tabular}{|l|c|c|c|c|}
\hline \multicolumn{1}{|c|}{ regions } & tot & $N$ & $A$ & $U$ \\
\hline Abruzzo & 22 & 8 & - & 14 \\
\hline Basilicata & 6 & - & - & 6 \\
\hline Calabria & 8 & 6 & 1 & 1 \\
\hline Campania & 246 & 23 & 174 & 49 \\
\hline Emilia Romagna & 6 & 3 & 1 & 2 \\
\hline Friuli Venezia Giulia & 3 & 1 & - & 2 \\
\hline Lazio & 107 & 67 & 5 & 35 \\
\hline Liguria & 4 & 3 & - & 1 \\
\hline Lombardia & 1 & - & - & 1 \\
\hline Molise & - & - & - & - \\
\hline Piemonte & 1 & - & - & 1 \\
\hline Puglia & 88 & 29 & 53 & 6 \\
\hline Sardegna & 9 & - & 3 & 6 \\
\hline Sicilia & 117 & 1 & 111 & 5 \\
\hline Toscana & 13 & 6 & 2 & 5 \\
\hline Trentino Alto Adige & 1 & - & - & 1 \\
\hline Umbria & 10 & - & - & 10 \\
\hline Valle d'Aosta & - & - & - & - \\
\hline Veneto & 10 & 10 & - & - \\
\hline & $\mathbf{6 5 2}$ & $\mathbf{1 5 7}$ & $\mathbf{3 5 0}$ & $\mathbf{1 4 5}$ \\
\hline
\end{tabular}

Lazio, Sicily and Apulia will be by far the most affected by sinkhole problems, especially due to presence of man-made cavities.

It has, however, to be noted that small numbers in Table 1 do not necessarily correspond to non-occurrence of sinkholes, but rather to unavailability of a temporal reference (which, as before stated, is mandatory for inclusion of an event in the catalogue). In particular, the very low number of anthropogenic sinkholes in Latium (5) has to be noted, given the high frequency of events affecting many towns of this region, including Rome.

For many records in the database only qualitative figures are available about the damage produced. In 17 cases, sinkholes have caused fatalities (the highest toll has been 4 victims in a single event), whilst casualties (deaths and injured people) are documented in at least 26 cases. This is certainly an issue which needs to be better examined, since damage analysis is crucial for assessing the effects to the built-up setting of the phenomena occurred, and the resulting data might be used for delineating different scenarios in case of occurrence of further sinkholes, or re-activations of those already existing.

Apulia (Puglia) region (Figure 5) is here presented as an example of analysis of the catalogue at a higher degree of detail. Choice of the region was dictated by our activity in this territory about sinkholes, and the research we have been carrying out in the last 15 years. The first consequence of the good knowledge of this territory, and of our direct experience in many sinkhole events, is the high certainty in sinkhole location ( $70 \%$ of the sample; Figure 6); analogously, the accuracy in date of occurrence of the events reaches percentages of $83 \%$ for medium

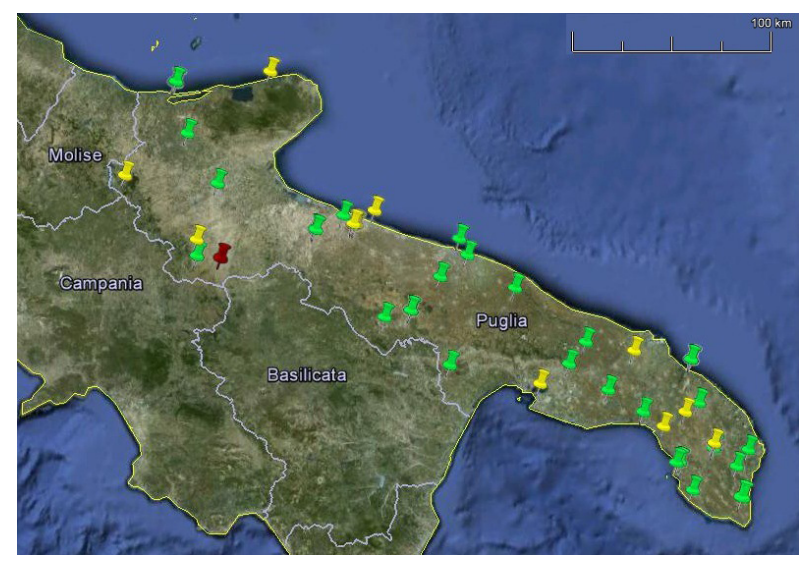

Figure 5. Sinkhole distribution in Apulia region $(n=88)$. 
to high accuracy (where medium means knowledge of month + year of occurrence, and high availability also of the hour of the event; Figure 6).

Looking at the chronological distribution of the events, the histogram $a$ in Figure 7 shows that, starting from 1925 (date of occurrence of the oldest documented event in the region, registered at Canosa di Puglia), an almost continuous increase in the number of sinkholes with temporal reference has been observed in Apulia, with slight decreases in this general pattern during the 1960s and 1980s . It has also to be noted that the last bar in the histogram covers a period of less than two years (2011 and the first ten month of 2012).

In the same figure, histogram $b$ is the detail for the time span 2000-2012: with the exception of 2001, 2002, and 2003, at least one sinkhole was documented each year, with a significant increase since 2006, and a
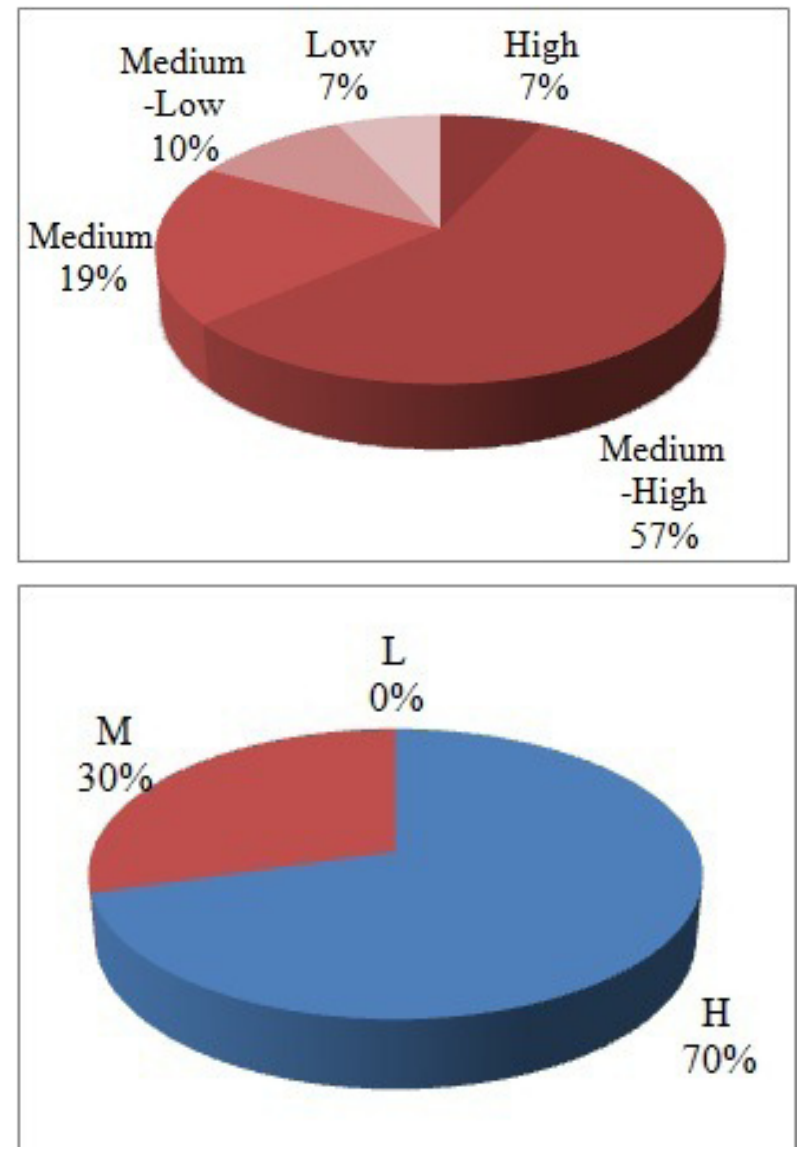

Figure 6. Pie charts illustrating for the Apulia sample $(n=88)$ the percentage of accuracy of date of occurrence of sinkholes (above), and the certainty in location of the sinkhole (below). small deflection in 2009. This may be in part due to a higher attention paid to the issue, after the first events at Altamura and, especially, that of March 29, 2007, at Gallipoli (Figure 8; Parise \& Fiore, 2011; Parise, 2012), and to a more careful record of the sinkhole occurrence. In fact, following the above cited events, the Basin Authority of Apulia (that is, the Regional Body in charge of dealing with hydrogeological hazards and defining the related regulations for land management) issued some

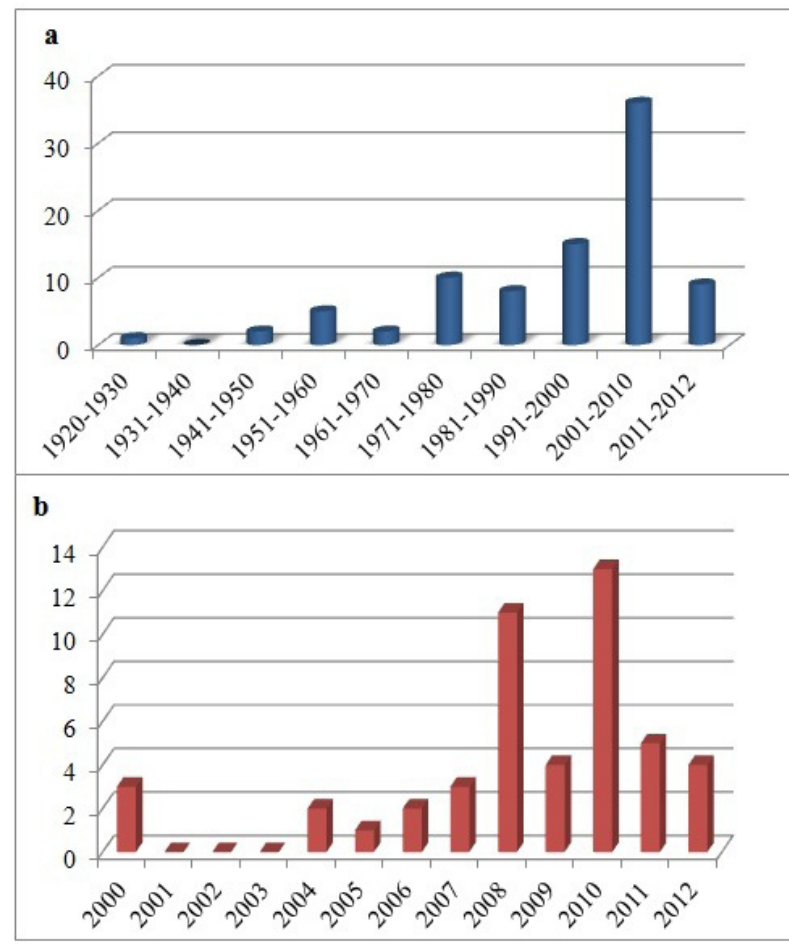

Figure 7. Chronological distribution of sinkholes in Apulia: a) histogram covering the time span from 1925 (oldest documented date) to the present day; b) histogram showing the detailed distribution in the time span 2000-2012.

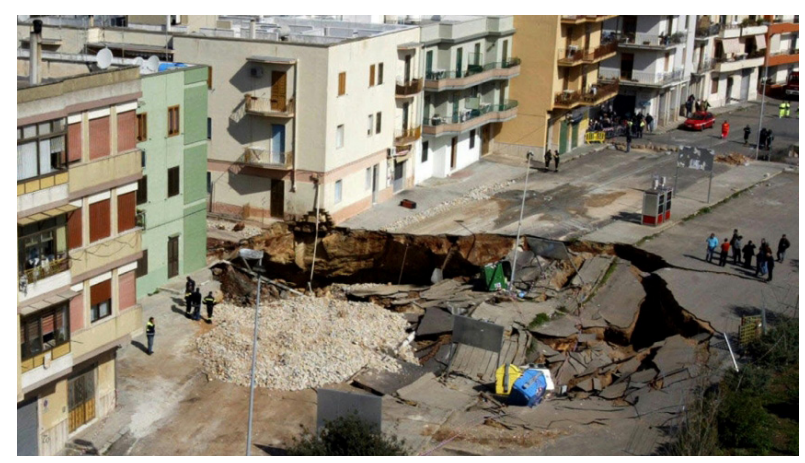

Figure 8. The March 29, 2007 sinkhole at Gallipoli (Apulia), a recent example of anthropogenic event due to an ancient underground quarry. 
regulations specifically to address the evaluation of the possibility of sinkhole occurrence in the case of presence of underground caves, of both natural and anthropogenic origin (Fiore, 2006).

In addition, the increase in attention on sinkholes was also a consequence of the severe crisis occurring at Marina di Lesina (Gargano Promontory, northern Apulia) where, starting from the 1990s, a high number of cover collapse and cover suffosion sinkholes (sensu Waltham et al., 2005) were recorded in the gypsum deposits bounding an artificial channel, the result of local hydrogeological changes caused by maintenance works of the canal in the coastal evaporite aquifer (Fidelibus et al., 2011).

\section{Future perspectives}

The catalogue of sinkholes here presented represents the first example available in Italy about sinkholes, specifically focused on time of occurrence of the events. At the same time, it differs from other databases on the same topic, for providing a clear discrimination
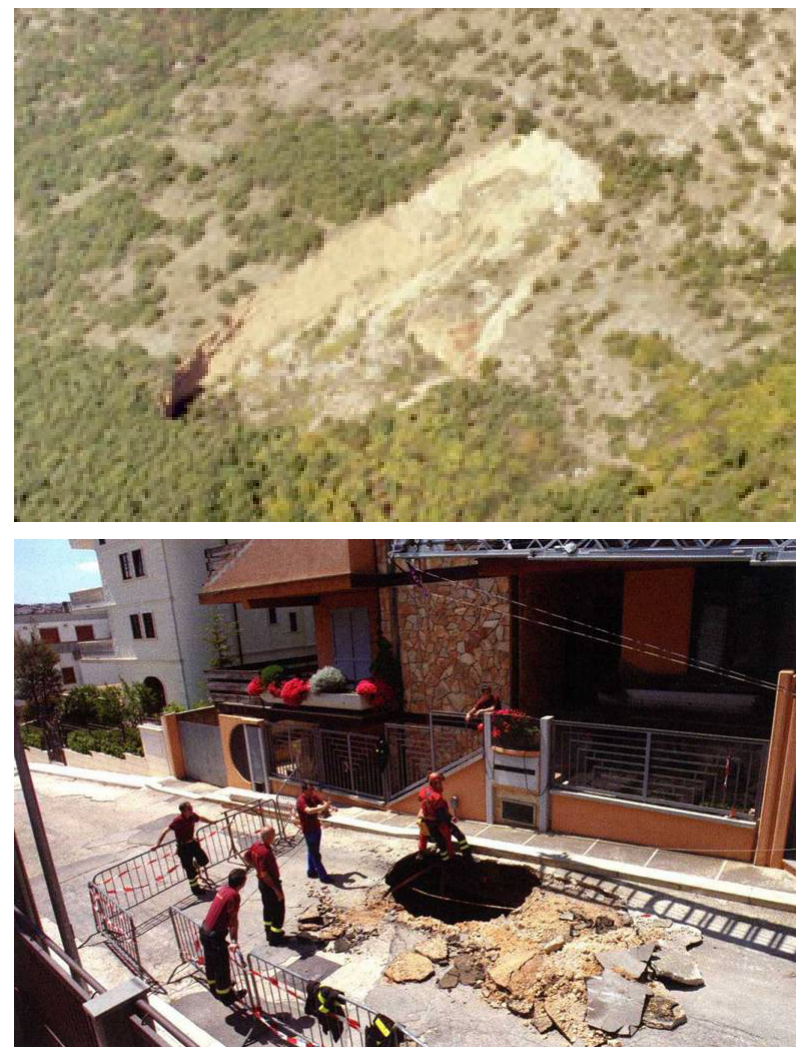

between sinkholes related to natural karst caves (natural sinkholes) and those linked to cavities realized by man (anthropogenic sinkholes). It is our firm belief that the two elements above are of crucial importance for a better understanding of the sinkhole hazard and risk. Knowing dates of the events represents the necessary element for definition of the hazard, whilst occurrence of natural or anthropogenic sinkholes may determine very different scenarios to be faced.

On the other hand, we are well aware that in terms of civil protection issues, it is very important to take into account the analysis of all those events which have caused damage to the society, regardless of their origin as natural or artificial sinkholes. In this sense, collection of data about the intensity of the consequences of sinkholes, with particular regard to number of fatalities and number of casualties appears to be the main goal, since these data are a direct, quantitative measure of the intensity of a disaster, and can be used to evaluate individual and societal risk quantitatively (Fell \& Hartford, 1997; Guzzetti et al., 2005).
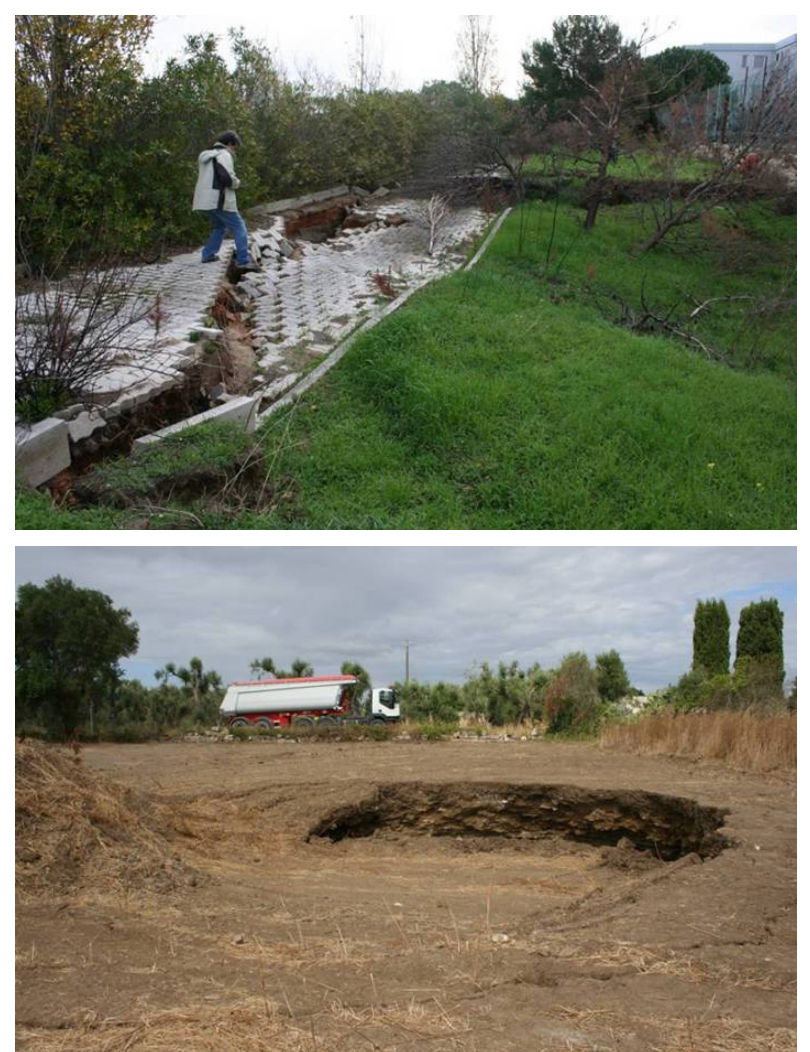

Figure 9. Examples of sinkholes, of natural (upper pictures) and anthropogenic (lower pictures) origin. Above left: Pianelle sinkhole (Campania region), triggered by the November 23, 1980 earthquake. Above right: one of the many sinkholes in the gypsum deposits of Marina di Lesina (Apulia). Below: sinkholes due to presence of underground quarries at Altamura (left; photo courtesy of CARS) and Cutrofiano (right), both in Apulia. 
As next steps, we intend therefore to complete the collection of data of the catalogue, since some regions are evidently less covered than others so far (see Figure 1 and Table 1), and there is definitely space for further data entries. After that, we will perform statistical analyses on the database, to establish the rate of occurrence of sinkholes for the whole Italian territory, and for specific regions or areas that might appear as particularly susceptible to this type of phenomena.

Spatial persistence of sinkholes, that is the occurrence of multiple events at the same site, will also be examined, as a very important element in the effort to evaluate the sinkhole hazard. At the same time, the effects of land use changes, including variations in the flow of surface and ground waters, will represent one of the main issues to investigate, as a likely factor inducing the occurrence of sinkholes.

Further, specific analysis will be performed in urban areas that appear to be the most affected by anthropogenic sinkholes; this is the case, for instance, of Rome, Naples (Guarino \& Nisio, 2012), Palermo (Sottile, 2010), but also of many other minor towns in several regions of Italy.

Given the consequences on the built-up areas (Figure 9), the outcomes of the research will be managed in strict collaboration with the Civil Protection Department, aimed at taking into account the sinkhole hazard in a geologically fragile and highly vulnerable territory such as Italy.

\section{References}

Benson RC, Yuhr L, Kaufmann RD. 2003. Assessing the risk of karst subsidence and collapse. Proc. 9th Multidisciplinary Conf. on Sinkholes and the Engineering and Environmental Impact of Karst, Huntsville, Alabama, ASCE publ. 122, p. 31-39.

Boschi E, Guidoboni E, Ferrari G, Mariotti D, Valensise G, Gasperini P. (editors). 2000. Catalogue of strong italian earthquakes from 461 b.C. to 1997. Annali di Geofisica 43 (4).

Brinkmann R, Parise M. 2010. The timing of sinkhole formation in Tampa and Orlando, Florida. The Florida Geographer 41: 22-38.

Buchignani V, D’Amato Avanzi G, Giannecchini R, Puccinelli A. 2008. Evaporite karst and sinkholes: a synthesis on the case of Camaiore (Italy). Environmental Geology 53 (5): 1033-1044.
Calcaterra D, Parise M. 2001. The contribution of historical information in the assessment of the landslide hazard. In: Glade T, Albini P, Frances F, editors. The Use of Historical Data in Natural Hazard Assessments. Advances in Natural and Technological Hazards Research: Kluwer Academic Publishers, 17: p. 201-217.

Calcaterra D, Parise M, Palma B. 2003. Combining historical and geological data for the assessment of the landslide hazard: a case study from Campania, Italy. Natural Hazards and Earth System Sciences 3 (1/2): 3-16.

Del Prete S, Iovine G, Parise M, Santo A. 2010. Origin and distribution of different types of sinkholes in the plain areas of Southern Italy. Geodinamica Acta 23 (1/3): 113-127.

Diederichs MS, Kaiser PK. 1999a. Stability of large excavations in laminated hard rock masses: the voussoir analogue revisited. Int J Rock Mechanics Mining Sciences 36: 97-117.

Diederichs MS, Kaiser PK. 1999b. Tensile strength and abutment relaxation as failure control mechanisms in underground excavations. Int J Rock Mechanics Mining Sciences 36: 69-96.

Festa V, Fiore A, Parise M, Siniscalchi A. 2012. Sinkhole evolution in the Apulian karst of southern Italy: a case study, with some considerations on sinkhole hazards. Journal of Cave and Karst Studies 74 (2): 137-147.

Fidelibus MD, Gutierrez F, Spilotro G. 2011. Humaninduced hydrogeological changes and sinkholes in the coastal gypsum karst of Lesina Marina area (Foggia province, Italy). Engineering Geology 118 (1-2): 1-19.

Fiore A. 2006. Pericolosità geologica connessa alla presenza di cavità sotterranee. Atto di indirizzo dell'Autorità di Bacino della Puglia. Geologi \& Territorio, 1-2-3: 3-11.

Gasperini P, Valensise G. 2000. From earthquake intensities to earthquake sources: extending the contribution of historical seismology to seismotectonic studies. Annali di Geofisica 43 (4): 765-785.

Glade T, Albini P, Frances F, editors 2001. The Use of Historical Data in Natural Hazard Assessments. Advances in Natural and Technological Hazards Research: Kluwer Academic Publishers, 17.

Guarino P, Nisio S. 2012. Anthropogenic sinkholes in the territory of the city of Naples. Journal of Physics and Chemistry of the Earth 49: 92-102.

Guzzetti F, 2000. Landslide fatalities and evaluation of landslide risk in Italy. Engng Geology 58: 89-107.

Guzzetti F, Cardinali M, Reichenbach P. 1994. The AVI Project: a bibliographical and archive inventory of landslides and floods in Italy. Environmental Management 18 (4): 623-633. 
Guzzetti F, Salvati P, Stark CP. 2005. Evaluation of risk to the population posed by natural hazards in Italy. In: Hungr O, Fell R, Couture R, Eberhardt E, editors. Landslide risk management. Taylor \& Francis Group, London: p. 381-389.

Fell R, Hartford D. 1997. Landslide risk management. In: Cruden DM, Fell R, editors. Landslide risk assessment. Balkema, Rotterdam: p. 51-109.

Italian Web Sinkhole Database [Internet]. 2012. Rome: University of Rome Tre; [cited 2012 Oct 26]. Available from: http://host.uniroma3.it/laboratori/ idrogeologia/iwsd.php

Kowalski WC. 1991. Engineering geological aspects of different types of karst corrosion and fracture generation in karst masses. Bull. IAEG 44: 35-46.

Lanaro F. 2000. A random field model for surface roughness and aperture of rock fractures. Int $\mathrm{J}$ Rock Mechanics Mining Sciences 37: 1195-1210.

Liu D, Wang S, Li L. 2000. Investigation of fracture behaviour during rock mass failure. Int J Rock Mechanics Mining Sciences 37: 489-497.

Margiotta S, Negri S, Parise M, Valloni R. 2012. Mapping the susceptibility to sinkholes in coastal areas, based on stratigraphy, geomorphology and geophysics. Natural Hazards 62 (2): 657-676.

Nisio S, editor. 2008. I fenomeni naturali di sinkhole nelle aree di pianura italiane. Memorie Descrittive della Carta Geologica d'Italia, 85.

Parise M. 2008. Rock failures in karst. In: Cheng Z, Zhang J, Li Z, Wu F, Ho K., editors. Landslides and Engineered Slopes. Proceedings 10th International Symposium on Landslides, Xi' an (China), June 30 - July 4, 2008. p. 275-280.

Parise M. 2012. A present risk from past activities: sinkhole occurrence above underground quarries. Carbonates and Evaporites 27 (2): 109-118.

Parise M, Fiore A. 2011. Chronology of sinkhole events in Apulia, Italy. Geophys. Res. Abst. 13: 3225.

Parise M, Lollino P. 2011. A preliminary analysis of failure mechanisms in karst and man-made underground caves in Southern Italy. Geomorphology 134 (1-2): 132-143.

Parise M, Perrone A, Violante C, Stewart JP, Simonelli A, Guzzetti F. 2010. Activity of the Italian National Research Council in the aftermath of the 6 April 2009 Abruzzo earthquake: the Sinizzo Lake case study. Proc. 2nd International Workshop "Catastrophic sinkholes in the natural and anthropogenic environment", Rome: p. 623-641.

Pepe P, Pentimone N, Garziano G, Martimucci V, Parise M. 2013. Lessons learned from occurrence of sinkholes related to man-made cavities in a town of southern Italy. These proceedings.
Pine RJ, Coggan JS, Flynn ZN, Elmo D. 2006. The development of a new numerical modelling approach for naturally fractured rock masses. Rock Mechanics Rock Engng 39 (5): 395-419.

Salvati P, Bianchi C, Rossi M, Guzzetti F. 2010. Societal landslide and flood risk in Italy. Natural Hazards Earth System Sciences 10: 465-483.

Sinkhole Project [Internet]. 2012. Rome: ISPRA; [cited 2012 Oct 20]. Available from: http://isprambiente. gov.it/it/progetti/il-progetto-sinkhole

Sottile R. 2010. Problematiche geologiche legate agli sprofondamenti in area urbana. L'esempio della città di Palermo [bachelor thesis]. Palermo: Palermo University. 248 p.

Starzec P, Tsang CF. 2002. Use of fracture-intersection density for predicting the volume of unstable blocks in underground openings. Int J Rock Mechanics Mining Sciences 39: 807-813.

Taviani M, Angeletti L, Campiani E, Ceregato A, Foglini F, Maselli V, Morsilli M, Parise M, Trincardi F. 2012. Drowned karst landscapes offshore the Apulian Margin (Southern Adriatic Sea, Italy). J. Cave Karst Studies 74 (2): 197-212.

Varnes, DJ. 1984. Landslide hazard zonation: a review of principles and practice. Unesco, Paris: pp. 63.

Waltham T, Bell F, Culshaw M. 2005. Sinkholes and subsidence. Karst and cavernous rocks in engineering and construction, pp. 382, Springer. 